\title{
Adubação nitrogenada em ciclos consecutivos e seu impacto na produção e na qualidade do pêssego
}

\author{
Gustavo Brunetto(1), George Wellington de Melo(2), João Kaminski(1) e Carlos Alberto Ceretta ${ }^{(1)}$
}

\begin{abstract}
(1)Universidade Federal de Santa Maria, Centro de Ciências Rurais, Programa de Pós-Graduação em Ciência do Solo, Dep. de Solos, Caixa Postal 221, CEP 97105-900 Santa Maria, RS. E-mail: brunetto.gustavo@gmail.com, jk@smail.ufsm.br, carlosceretta@smail.ufsm.br (2)Embrapa Uva e Vinho, Caixa Postal 130, Rua Livramento 515, CEP 95700-000 Bento Gonçalves, RS. E-mail: george@cnpuv.embrapa.br
\end{abstract}

Resumo - O objetivo deste trabalho foi avaliar o efeito da aplicação de $\mathrm{N}$ sobre o teor foliar do nutriente, o crescimento de ramos, a produção e a qualidade química e física dos frutos de pêssego. O experimento foi conduzido no período de 2000 a 2002, em um pomar de pessegueiro da cultivar Chimarrita, enxertada no portaenxerto Aldrighi, em Pinto Bandeira, RS, em um solo Cambissolo Húmico. Os tratamentos foram 0, 22, 44, 66 e $88 \mathrm{~kg} \mathrm{ha}^{-1}$ de $\mathrm{N}$ por ano. Em todas as safras, folhas foram coletadas para análise de $\mathrm{N}$ total. Após a queda das folhas, foi determinado o comprimento de ramos do ano. Na maturação, os frutos foram colhidos e foram determinados o diâmetro, a massa, a produção, o $\mathrm{N}$ total, os sólidos solúveis totais, a acidez total titulável e a firmeza da polpa, esta última repetida após pré-resfriamento com circulação forçada de ar e armazenamento em câmara fria. A aplicação de $\mathrm{N}$ em pessegueiros aumenta o teor do nutriente nas folhas e nos frutos. A adubação nitrogenada não afeta o comprimento dos ramos do ano, o diâmetro, a massa, a produção, a acidez total titulável e a firmeza da polpa dos frutos de pêssego.

Termos para indexação: Prunus persica, adubação nitrogenada, nutrição mineral.

\section{Nitrogen fertilization in serial cycles and its impact on yield and quality of peach}

\begin{abstract}
The objective of this work was to evaluate the effect of $\mathrm{N}$ fertilization on $\mathrm{N}$ content of the leaf, shoot growth, yield and on physico-chemical quality of peach fruits. The experiment was carried out from 2000 to 2002, in an orchard of peach trees, cv. Chimarrita, grafted on Aldrighi rootstock, at Pinto Bandeira city, in Rio Grande do Sul State, Southern Brazil, in a Haplumbrept soil. The treatments were 0, 22, 44, 66, and $88 \mathrm{~kg} \mathrm{ha}^{-1} \mathrm{~N}$ per year. In the growing seasons leaves were collected, oven-dried and analyzed for total $\mathrm{N}$, and the length of selected shoots was determined after leaf abscission. Fruits were collected when ripen, for the determination of diameter, mass, yield, total N, total soluble solids, total titratable acidity and pulp firmness. Remaining fruits were cooled through forced-air system and kept in cold storage for seven days, then pulp firmness was determined. $\mathrm{N}$ fertilization in peach trees increases $\mathrm{N}$ content in the leaves and in the fruits. $\mathrm{N}$ fertilization do not affect the length of shoots, and the diameter, mass, total titratable acidity and pulp firmness of peach fruits.
\end{abstract}

Index terms: Prunus persica, nitrogen fertilization, mineral nutrition.

\section{Introdução}

O Rio Grande do Sul possui a maior área, no Brasil, cultivada com pessegueiro. Os primeiros cultivos comerciais foram realizados na região sul do Estado, em solos com textura arenosa e com baixo teor de matéria orgânica, onde há necessidade de suplementação de nitrogênio para as culturas, via adubação. Com a ampliação da persicultura no Estado, áreas da região da Serra Gaúcha foram incorporadas nesse sistema de produção. Atualmente, esta região é a maior produtora de pêssego para o consumo in natura.
Os pomares são formados, em geral, por cultivares com frutos de polpa branca, entre elas, a Chimarrita, e se localizam em solos com textura média ou argilosa, com médio a alto teor de matéria orgânica, e superfície coberta com resíduos de plantas de cobertura, o que lhe confere alta capacidade de fornecimento de nitrogênio (N). Porém, nem sempre essas fontes naturais de $\mathrm{N}$ suprem a demanda da planta pelo nutriente. Por isso, torna-se necessária a aplicação de fertilizante nitrogenado mineral. Mas ele pode afetar o teor do nutriente nas folhas, o crescimento dos ramos do ano, o diâmetro e a massa dos frutos (Mattos et al., 1991; 
Tagliavini et al., 1996; Crisosto et al., 1997; Saenz et al., 1997; Lobit et al., 2001; Dolinski et al., 2005), além de alterar as características químicas do fruto, como o teor de N, os sólidos solúveis totais, a acidez total titulável, ou as características físicas, entre as quais a firmeza da polpa (Carvalho et al., 1989; Dolinski et al., 2005), o que indica a necessidade de estudos sobre os efeitos da aplicação de N, mesmo em solos tidos como de alta capacidade de suprimento deste nutriente para as plantas.

No Rio Grande do Sul e em Santa Catarina, a Comissão de Química e Fertilidade do Solo (Comissão de Química e Fertilidade do Solo, 2004) indica a dose de $\mathrm{N}$ para a cultura do pessegueiro, com base em seu teor total na folha, no crescimento dos ramos do ano e na produtividade esperada. Quando há necessidade de aplicação, recomenda-se o parcelamento de $\mathrm{N}$ durante o ciclo vegetativo-produtivo das plantas. Essa recomendação não considera os efeitos do $\mathrm{N}$ aplicado, sobre as características químicas e físicas dos frutos. Torna-se necessária a condução de estudos de eficiência da adubação nitrogenada sobre componentes de rendimento e da qualidade dos frutos produzidos, uma vez que trabalhos realizados na Serra Gaúcha e no Sudeste de Santa Catarina, com outras espécies de frutíferas, como a videira e a macieira, indicam que esses solos já possuem capacidade de suprimento de $\mathrm{N}$ suficiente para a manutenção de produtividade e do vigor das plantas (Dal Bó, 1992; Ernani \& Dias, 1999; Ernani et al., 2000; Brunetto et al., 2006).

O objetivo deste trabalho foi avaliar o efeito da aplicação de $\mathrm{N}$ sobre o teor do nutriente na folha, o crescimento de ramos, a produção e a qualidade química e física dos frutos de pêssego.

\section{Material e Métodos}

O trabalho foi conduzido nas safras agrícolas de 2000, 2001 e 2002, em um pomar comercial de pessegueiro (Prunus persica, L. Batsch), cultivar Chimarrita, enxertada no porta-enxerto Aldrighi, no Município de Pinto Bandeira, região fisiográfica da Serra Gaúcha, no Rio Grande do Sul, cujos dados de precipitação pluvial são apresentados na Tabela 1. Os pessegueiros foram plantados em 1995, com distância de 6 m entre linhas e $4 \mathrm{~m}$ entre plantas na linha e conduzidos em taça com quatro pernas.

O solo da área experimental é um Cambissolo Húmico (Embrapa, 1999), com declividade de aproximadamente $3 \%$. O solo da camada de $0-20 \mathrm{~cm}$ apresentou teor de argila de $270 \mathrm{~g} \mathrm{~kg}^{-1}$, pelo método da pipeta (Embrapa, 1997). Os resultados da análise química do solo (Tedesco et al., 1995) foram: $\mathrm{pH}$ em água, 6,3; índice SMP, 5,7; MO, $54 \mathrm{~g} \mathrm{~kg}^{-1} ; \mathrm{Ca}, \mathrm{Mg}$ e Al trocável, 9,30, 4,10 e $0,0 \mathrm{cmol}_{\mathrm{c}} \mathrm{kg}^{-1}$, respectivamente, extraídos por $\mathrm{KCl}$ $1 \mathrm{~mol} \mathrm{~L}^{-1} ; \mathrm{P}, 113 \mathrm{mg} \mathrm{kg}^{-1} ; \mathrm{K}, 105 \mathrm{mg} \mathrm{kg}^{-1}$, extraídos com duplo ácido (Mehlich 1); capacidade de troca cátions (CTC) a pH 7, 19,8 $\mathrm{cmol}_{\mathrm{c}} \mathrm{kg}^{-1}$; e saturação por bases da CTC a pH 7, 69,9\%.

Os tratamentos consistiram da aplicação de $0,22,44$, 66 e $88 \mathrm{~kg} \mathrm{ha}^{-1}$ de $\mathrm{N}$ por ano de forma parcelada: $50 \%$ no início da brotação (agosto); $30 \%$ após o raleio dos frutos (outubro); e 20\% após a colheita (janeiro), conforme estabelecido pela Comissão de Química e Fertilidade do Solo (2004). A fonte de N foi a uréia (45\% de N), aplicada sobre a superfície do solo, sem incorporação, em uma faixa de $2 \mathrm{~m}$ de largura, a partir do caule da planta, acompanhando a linha de plantio. $\mathrm{O}$ delineamento experimental usado foi o de blocos ao acaso, com quatro repetições, e cada parcela foi formada por seis plantas (quatro avaliadas), distribuídas ao longo da linha de plantio.

Os pessegueiros da área experimental receberam a aplicação de fertilizantes (exceto $\mathrm{N}$ ), fungicidas e inseticidas, ao longo do ciclo vegetativo e produtivo das plantas, poda de inverno (junho), e raleio manual de frutos (outubro). Como a cobertura vegetal pode afetar a disponibilidade de $\mathrm{N}$, uma faixa de $2 \mathrm{~m}$ ao longo da fila de plantio foi mantida isenta de plantas daninhas, pela aplicação de herbicida (glifosato), logo após a queda das folhas das plantas.

Nas três safras agrícolas, foram coletadas folhas completas (limbo+pecíolo), da parte média dos ramos do ano, nos diferentes lados das plantas, na décima quarta semana após a plena floração (Comissão de Química e Fertilidade do Solo, 2004). Em cada ano,

Tabela 1. Precipitação pluvial (mm) durante o período de condução do experimento.

\begin{tabular}{lrrr}
\hline Mês & \multicolumn{3}{c}{ Safra agrícola } \\
\cline { 2 - 4 } & 2000 & 2001 & 2002 \\
\hline Janeiro & 166,6 & 214,1 & 161,6 \\
Fevereiro & 60,0 & 60,0 & 62,4 \\
Março & 172,3 & 122,4 & 167,8 \\
Abril & 106,8 & 262,2 & 189,2 \\
Maio & 51,2 & 104,4 & 163,8 \\
Junho & 175,4 & 129,2 & 232,4 \\
Julho & 139,8 & 285,2 & 175,8 \\
Agosto & 123,4 & 44,6 & 203,2 \\
Setembro & 180,4 & 245,8 & 162,6 \\
Outubro & 235,0 & 159,2 & 313,2 \\
Novembro & 132,0 & 209,4 & 166,4 \\
Dezembro & 171,8 & 138,4 & 201,8 \\
\hline Total & $1.714,7$ & $1.974,9$ & $2.200,2$ \\
\hline
\end{tabular}


depois da queda das folhas, foi determinado o comprimento de 50 ramos do ano em cada planta, previamente marcados no início do ciclo vegetativo. Na plena maturação dos frutos (dezembro), foram colhidos e determinados o diâmetro, a massa e a produção. Em seguida, um terço dos frutos foi triturado e preparado para a determinação de $\mathrm{N}$ total (Tedesco et al., 1995). Outro terço dos frutos foi esmagado e, no suco, foram determinados: os sólidos solúveis totais, com refratômetro digital de bancada com controle de temperatura; a acidez total titulável, com titulometria de neutralização com $\mathrm{NaOH} 0,1 \mathrm{~N}$, tendo-se usado a fenolftaleína como indicador; e a firmeza da polpa, com penetrômetro de mão com ponteira de $8 \mathrm{~mm}$. O último terço dos frutos foi pré-resfriado com circulação forçada de ar, acondicionado em caixas de plástico de $20 \mathrm{~kg}$ e mantido em armazenamento refrigerado, em câmara fria comercial a $-0,5 \pm 0^{\circ} \mathrm{C}$ e $90 \pm 5 \%$ de umidade relativa, durante sete dias e, em seguida, foi determinada novamente a firmeza da polpa.

Os resultados obtidos foram submetidos à análise de variância e, quando os efeitos foram significativos, foram ajustadas as equações de regressão, tendo-se testado os modelos linear e quadrático pelo teste $\mathrm{F}$, dos quais foi escolhido aquele com significância maior que $95 \%$.

\section{Resultados e Discussão}

Apesar de as doses de $\mathrm{N}$ terem causado o aumento de forma linear das porcentagens do nutriente nas folhas, em todas as safras agrícolas (Tabela 2) (Mattos et al., 1991; Crisosto et al., 1997; Dolinski et al., 2005), os

Tabela 2. Nitrogênio nas folhas (\%) e comprimento (cm) dos ramos do ano, de pessegueiro cultivar Chimarrita, submetido à adubação nitrogenada em três safras consecutivas.

\begin{tabular}{|c|c|c|c|}
\hline \multirow{2}{*}{$\begin{array}{l}\text { Dose de } \mathrm{N} \\
\left(\mathrm{kg} \mathrm{ha}^{-1} \mathrm{ano}^{-1}\right)\end{array}$} & \multicolumn{3}{|c|}{ Safra agrícola } \\
\hline & 2000 & 2001 & 2002 \\
\hline & \multicolumn{3}{|c|}{ Nitrogênio na folha } \\
\hline 0 & $2,10^{(1)}$ & $2,09^{(2)}$ & $2,10^{(3)}$ \\
\hline 22 & 2,25 & 2,32 & 2,32 \\
\hline 44 & 2,12 & 2,10 & 2,10 \\
\hline 66 & 2,29 & 2,29 & 2,29 \\
\hline 88 & 2,45 & 2,41 & 2,41 \\
\hline \multirow[t]{2}{*}{ CV (\%) } & 7,42 & 7,48 & 8,03 \\
\hline & \multicolumn{3}{|c|}{ Comprimento do ramo do ano } \\
\hline 0 & $46^{\mathrm{ns}}$ & $45^{\mathrm{ns}}$ & $46^{\mathrm{ns}}$ \\
\hline 22 & 46 & 45 & 46 \\
\hline 44 & 45 & 45 & 45 \\
\hline 66 & 46 & 45 & 46 \\
\hline 88 & 46 & 46 & 46 \\
\hline CV (\%) & 2,2 & 2,0 & 1,8 \\
\hline
\end{tabular}

teores ficaram abaixo do normal na faixa de interpretação, entre 1,89 e 3,25\% (Comissão de Química e Fertilidade do Solo, 2004).

O comprimento dos ramos do ano sempre foi superior a $45 \mathrm{~cm}$ e não foi alterado pela aplicação de $\mathrm{N}$, nas três safras (Tabela 2). Raseira \& Nakasu (1998) destacam que o comprimento dos ramos do ano entre 40 e $60 \mathrm{~cm}$ pode ser descrito como vigoroso.

Assim, pode-se inferir que mesmo sem aplicação de $\mathrm{N}$, as plantas alcançaram vigor suficiente para permitir produções de fruto com tamanho médio, com diâmetro entre 5 e $6 \mathrm{~cm}$ e massa entre 80 e $110 \mathrm{~g}$ (Raseira \& Nakasu, 1998), o que é desejado pelo mercado consumidor. Por isso, a aplicação de $\mathrm{N}$ não afetou o diâmetro do fruto, a sua massa e, nem tão pouco, a produção, em todas as safras (Tabela 3). Isso se deve ao teor de matéria orgânica que, nesse solo foi de $54 \mathrm{~g} \mathrm{~kg}^{-1}$, o que o coloca na faixa alta de suprimento de N (Comissão de Química e Fertilidade do Solo, 2004). Porém, mesmo nessa condição, as plantas também absorvem $\mathrm{N}$ do fertilizante, representado pela porcentagem de $\mathrm{N}$ nas folhas. Entretanto não alteram o crescimento dos ramos do ano nem a produção e os seus componentes, como o diâmetro e a massa do fruto.

A aplicação de $\mathrm{N}$ aumentou de forma linear as porcentagens de $\mathrm{N}$ no fruto (Tabela 4), mesmo

Tabela 3. Diâmetro $(\mathrm{cm})$, massa $(\mathrm{g})$ e produção de frutos de pessegueiro (kg por planta), cultivar Chimarrita, submetido à adubação nitrogenada em três safras consecutivas.

\begin{tabular}{|c|c|c|c|}
\hline \multirow{2}{*}{$\begin{array}{l}\text { Dose de N } \\
\left(\mathrm{kg} \mathrm{ha}^{-1} \text { ano }^{-1}\right)\end{array}$} & \multicolumn{3}{|c|}{ Safra agrícola } \\
\hline & 2000 & 2001 & 2002 \\
\hline & \multicolumn{3}{|c|}{ Diâmetro do fruto } \\
\hline 0 & $5,68^{\mathrm{ns}}$ & $5,48^{\text {ns }}$ & $5,62^{\text {ns }}$ \\
\hline 22 & 5,52 & 5,60 & 5,63 \\
\hline 44 & 5,45 & 5,45 & 5,53 \\
\hline 66 & 5,66 & 5,55 & 5,60 \\
\hline 88 & 5,55 & 5,46 & 5,65 \\
\hline \multirow[t]{2}{*}{$\mathrm{CV}(\%)$} & 3,72 & 4,84 & 2,32 \\
\hline & \multicolumn{3}{|c|}{ Massa do fruto } \\
\hline 0 & $90,20^{\mathrm{ns}}$ & $90,32^{\text {ns }}$ & $90,10^{\mathrm{ns}}$ \\
\hline 22 & 94,40 & 93,92 & 93,83 \\
\hline 44 & 89,27 & 89,30 & 89,42 \\
\hline 66 & 98,07 & 98,27 & 97,77 \\
\hline 88 & 90,87 & 91,02 & 90,32 \\
\hline \multirow[t]{2}{*}{$\mathrm{CV}(\%)$} & 10,45 & 10,67 & 10,45 \\
\hline & \multicolumn{3}{|c|}{ Produção } \\
\hline 0 & $45,10^{\mathrm{ns}}$ & $45,16^{\mathrm{ns}}$ & $45,05^{\mathrm{ns}}$ \\
\hline 22 & 47,20 & 46,96 & 46,92 \\
\hline 44 & 44,63 & 44,65 & 44,71 \\
\hline 66 & 49,03 & 49,13 & 48,88 \\
\hline 88 & 45,43 & 45,51 & 45,16 \\
\hline $\mathrm{CV}(\%)$ & 10,46 & 10,50 & 10,30 \\
\hline
\end{tabular}

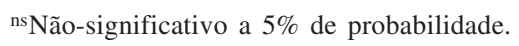


comportamento da porcentagem de $\mathrm{N}$ nas folhas (Tabela 2). Os valores de sólidos solúveis totais, indicadores da quantidade de açúcar no fruto, não foram afetados pelas doses de $\mathrm{N}$ na safra 2000 , porém na safra 2001 aumentaram de forma linear, e em 2002 diminuíram de forma linear (Tabela 4), o que pode estar associado à maior absorção de água pelas plantas, por causa da maior precipitação pluvial (Tabela 1), que pode ter diluído os açúcares no fruto. Convém relatar que em todas as doses de $\mathrm{N}$ em safras agrícolas, os valores de sólidos

Tabela 4. Nitrogênio no fruto (\%), sólidos solúveis totais ( ${ }^{\circ}$ Brix), acidez total titulável (mg de ácido cítrico por $100 \mathrm{~g}$ de polpa), firmeza da polpa na colheita $\left(\mathrm{lb} \mathrm{pl}^{-2}\right)$, e firmeza da polpa $\left(\mathrm{lb} \mathrm{pl}^{-2}\right)$ após 7 dias de armazenamento refrigerado, em frutos de pessegueiro cultivar Chimarrita, submetido à adubação nitrogenada em três safras consecutivas.

\begin{tabular}{|c|c|c|c|}
\hline \multirow{2}{*}{$\begin{array}{l}\text { Dose de } \mathrm{N} \\
\left(\mathrm{kg} \mathrm{ha}^{-1} \mathrm{ano}^{-1}\right)\end{array}$} & \multicolumn{3}{|c|}{ Safra agrícola } \\
\hline & 2000 & 2001 & 2002 \\
\hline & \multicolumn{3}{|c|}{ Nitrogênio no fruto } \\
\hline 0 & $0,51^{(1)}$ & $0,50^{(2)}$ & $0,48^{(3)}$ \\
\hline 22 & 0,55 & 0,54 & 0,56 \\
\hline 44 & 0,53 & 0,54 & 0,49 \\
\hline 66 & 0,64 & 0,64 & 0,64 \\
\hline 88 & 0,79 & 0,79 & 0,79 \\
\hline \multirow[t]{2}{*}{ CV (\%) } & 17,93 & 14,94 & 17,44 \\
\hline & \multicolumn{3}{|c|}{ Sólidos solúveis totais } \\
\hline 0 & $11,80^{\mathrm{ns}}$ & $12,32^{(4)}$ & $11,91^{(5)}$ \\
\hline 22 & 11,08 & 12,15 & 11,11 \\
\hline 44 & 11,18 & 11,94 & 11,25 \\
\hline 66 & 11,50 & 12,43 & 11,19 \\
\hline 88 & 11,05 & 12,67 & 10,93 \\
\hline \multirow[t]{2}{*}{$\mathrm{CV}(\%)$} & 5,91 & 3,02 & 3,53 \\
\hline & \multicolumn{3}{|c|}{ Acidez total titulável } \\
\hline 0 & $5,56^{\mathrm{ns}}$ & $5,55^{\text {ns }}$ & $5,99^{\mathrm{ns}}$ \\
\hline 22 & 5,73 & 5,31 & 5,52 \\
\hline 44 & 5,68 & 5,18 & 5,58 \\
\hline 66 & 6,12 & 5,42 & 6,06 \\
\hline 88 & 5,89 & 5,75 & 6,00 \\
\hline \multirow[t]{2}{*}{ CV $(\%)$} & 6,12 & 10,62 & 9,00 \\
\hline & \multicolumn{3}{|c|}{ Firmeza da polpa na colheita } \\
\hline 0 & $15,14^{\mathrm{ns}}$ & $15,11^{\mathrm{ns}}$ & $14,06^{\mathrm{ns}}$ \\
\hline 22 & 15,41 & 15,21 & 14,57 \\
\hline 44 & 15,06 & 14,87 & 14,53 \\
\hline 66 & 15,43 & 15,29 & 14,24 \\
\hline 88 & 15,08 & 15,18 & 14,58 \\
\hline \multirow[t]{2}{*}{$\mathrm{CV}(\%)$} & 6,92 & 5,12 & 8,61 \\
\hline & \multicolumn{3}{|c|}{$\begin{array}{l}\text { Firmeza da polpa após } 7 \text { dias } \\
\text { de armazenamento refrigerado }\end{array}$} \\
\hline 0 & $2,81^{\mathrm{ns}}$ & $2,27^{\mathrm{ns}}$ & $2,84^{\mathrm{ns}}$ \\
\hline 22 & 3,02 & 2,41 & 2,52 \\
\hline 44 & 2,70 & 2,21 & 2,36 \\
\hline 66 & 2,80 & 2,33 & 2,46 \\
\hline 88 & 2,73 & 2,12 & 2,54 \\
\hline $\mathrm{CV}(\%)$ & 18,01 & 13,33 & 16,51 \\
\hline
\end{tabular}

${ }^{(1)} \mathrm{y}=0,474+0,0030 \mathrm{x} \quad\left(\mathrm{R}^{2}=0,79 *\right) . \quad{ }^{(2)} \mathrm{y}=0,466+0,0031 \mathrm{x}$ $\left(\mathrm{R}^{2}=0,84^{*}\right) .{ }^{(3)} \mathrm{y}=0,452+0,0032 \mathrm{x}\left(\mathrm{R}^{2}=0,74^{*}\right) .{ }^{(4)} \mathrm{y}=12,106+$ $0,0045 x\left(\mathrm{R}^{2}=0,31 *\right) .{ }^{(5)} \mathrm{y}=11,654-0,0084 x\left(\mathrm{R}^{2}=0,63 *\right)$.

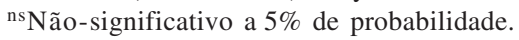

solúveis totais foram próximos aos preconizados por Raseira \& Nakasu (1998) como normais para os frutos da cultivar Chimarrita, que seriam de 12 a $15^{\circ}$ Brix. Resultados de valores de sólidos solúveis totais diferentes, entre safras agrícolas, são obtidos em experimentos com adição de $\mathrm{N}$ em espécies frutíferas (Carvalho et al., 1989), e estão associados com as manifestações climáticas, como veranicos, variações de temperatura e distribuição de chuvas.

A adubação nitrogenada também não afetou os valores de acidez total titulável e de firmeza da polpa dos frutos, tanto após a colheita, como depois de sete dias de armazenamento refrigerado em câmara fria (Tabela 4). Convém ressaltar que, primeiro, os menores valores de firmeza da polpa dos frutos, após sete dias de armazenamento refrigerado, comparativamente aos valores de firmeza da polpa após a colheita, podem ser atribuídos ao avanço do amadurecimento dos frutos (que causa a degradação de substâncias pécticas que compõem a parede celular das células vegetais) e ao amolecimento da polpa. Segundo, a não interferência do $\mathrm{N}$ aplicado ao solo na firmeza da polpa dos frutos deve-se, além de outros atributos do fruto, ao diâmetro e à massa (Tabela 3) que, ao manter volume celular similar, proporciona a mesma resistência à penetração (Sams, 1999).

A baixa resposta do pessegueiro à adubação nitrogenada deve-se às condições de umidade no solo, que foram boas, e às temperaturas amenas durante todos os meses do período estudado. Conforme Agehara \& Warncke (2005), isso favorece a mineralização da matéria orgânica do solo e a decomposição de resíduos vegetais sobre a superfície, nas entrelinhas dos pessegueiros, como resíduos de plantas de cobertura, de ramos podados e de folhas senescentes dos pessegueiros, os quais disponibilizam quantidades suficientes para a produção de pêssego. Dados obtidos por Dal Bó (1992) e Brunetto et al. (2006), com a videira, por Ernani \& Dias (1999) e Ernani et al. (2000) com a macieira, todos realizados em solos com médio e alto teor de matéria orgânica da região da Serra Gaúcha e Sudeste de Santa Catarina, mostram que a matéria orgânica presente no solo pode fornecer o $\mathrm{N}$ necessário para a produção e desenvolvimento das plantas e dispensa a adubação nitrogenada nessas condições edafoclimáticas. Entretanto, a adubação nitrogenada 
anual para pessegueiro, com base no teor de $\mathrm{N}$ na folha, no crescimento dos ramos do ano e na expectativa de produtividade, deve ser reavaliada em experimentos de longa duração, em todas as regiões produtoras.

\section{Conclusões}

1. A aplicação de nitrogênio, em pessegueiros da cultivar Chimarrita, aumenta o teor do nutriente nas folhas e nos frutos.

2. A adubação nitrogenada não afeta o comprimento dos ramos do ano, o diâmetro, a massa, a produção, a acidez total titulável e a firmeza da polpa dos frutos de pêssego.

\section{Agradecimentos}

Ao CNPq, pela bolsa concedida; aos laboratoristas Volmir Scanagatta e Alexandre Mussnich, do Laboratório de Análise de Solo e Tecido da Embrapa Uva e Vinho, pelo auxílio na execução do experimento e pelas análises de solo e de tecido; aos laboratoristas do Laboratório de Pós-colheita da Embrapa Uva e Vinho, pelo auxílio nas análises químicas e físicas de fruto.

\section{Referências}

AGEHARA, S.; WARNCKE, D.D. Soil moisture and temperature effects on nitrogen release from organic nitrogen sources. Soil Science Society of America Journal, v.69, p.1844-1855, 2005.

BRUNETTO, G.; KAMINSKI, J.; MELO, G.W.B.; BRUNING, F.S.; MALLMANN, F.J.K. Destino do nitrogênio em videiras 'Chardonnay' e 'Riesling Renano' quando aplicado no inchamento das gemas. Revista Brasileira de Fruticultura, v.28, p.497-500, 2006.

CARVALHO, S.A.; ROCHA, A.C.; TAVARES, E.D. Efeitos dos principais nutrientes na qualidade das frutas. Revista Brasileira de Fruticultura, v.11, p.35-44, 1989.

COMISSÃO DE QUÍMICA E FERTILIDADE DO SOLO. Manual de adubação e calagem para os Estados do Rio Grande do Sul e de Santa Catarina. 10.ed. Porto Alegre: SBCS-Núcleo Regional Sul/UFRGS, 2004. 400p.
CRISOSTO, C.H.; JOHNSON, R.S.; DEJONG, T. Orchard factors affecting postharvest stone fruit quality. HortScience, v.32, p.820823, 1997.

DAL BÓ, M.A. Efeito da adubação NPK na produção, qualidade da uva e nos teores foliares de nutrientes da videira. Revista Brasileira de Fruticultura, v.14, p.189-194, 1992.

DOLINSKI, M.A.; SERRAT, B.M.; MOTTA, A.C.V.; CUQUEL, F.L.; SOUZA, S.R.; MAY-DE MIO, L.L.; MONTEIRO, L.B. Produção, teor foliar e qualidade de frutos do pessegueiro 'Chimarrita' em função da adubação nitrogenada, na região da Lapa-PR. Revista Brasileira de Fruticultura, v.27, p.295-299, 2005.

EMBRAPA. Manual de métodos de análise de solo. Rio de Janeiro: Embrapa-CNPS, 1997. 212p.

EMBRAPA. Sistema brasileiro de classificação de solos. Rio de Janeiro: Embrapa-CNPS, 1999. 412p.

ERNANI, P.R.; DIAS, J. Soil nitrogen application in the spring did not increase apple yield. Ciência Rural, v.29, p.645-649, 1999.

ERNANI, P.R.; DIAS, J.; BORGES, M. A aplicação de nitrogênio ao solo em diferentes estádios não afetou o rendimento de frutos de cultivares de macieira. Ciência Rural, v.30, p.223-227, 2000.

LOBIT, P.; SOING, P.; GÉNARD, M.; HABIB, R. Effects of timing of nitrogen fertilization on shoot development in peach (Prunus persica) trees. Tree Physiology, v.21, p.35-42, 2001.

MATTOS, M.L.T.; FREIRE, C.J.S.; MAGNANI, M. Crescimento e teores foliares de N, P, K, Ca e Mg em pessegueiro cv. Diamante com diferentes níveis de $\mathrm{N}$ aplicado ao solo. Pesquisa Agropecuária Brasileira, v.26, p.1315-1321, 1991.

RASEIRA, M.C.B.; NAKASU, B.H. Cultivares: descrição e recomendação. In: MEDEIROS, C.A.B.; RASEIRA, M.C.B. (Ed.). A cultura do pessegueiro. Brasília: Embrapa-SPI; Pelotas: EmbrapaCPACT, 1998. p.29-99.

SAENZ, J.L.; DEJONG, T.M.; WEINBAUM, S.A. Nitrogen stimulated increases in peach yields are associated with extended fruit development period and increased fruit sink capacity. Journal of the American Society of Horticultural Science, v.122, p.772777, 1997.

SAMS, C.E. Preharvest factors affecting postharvest texture. Postharvest Biology and Technology, v.15, p.249-254, 1999.

TAGLIAVINI, M.; SCUDELLAZI, D.; MARANGONI, B.; TOSELLI, M. Nitrogen fertilization management in orchards to reconcile productivity and environmental aspects. Fertility Research, v.43, p.93-102, 1996.

TEDESCO, M.J.; GIANELLO, C.; BISSANI, C.; BOHNEN, H.; VOLKWEISS, S.J. Análise de solo, plantas e outros materiais. 2.ed. Porto Alegre: UFRGS, 1995. 174p. (Boletim Técnico, 5). 